ARTigo Original

Original ARTICLE

\title{
Detecção do DNA de Chlamydia trachomatis em Espondiloartropatias e Artrite Reumatóide $e^{(*)}$
}

\author{
Detection of Chlamydia trachomatis DNA in \\ Spondyloarthropathies and Rheumatoid Arthritis
}

\author{
Rafael Navarrete Fernandez ${ }^{(1)}$, Antônio Carlos Ximenes ${ }^{(2)}$, Maria de Fátima Costa Alves ${ }^{(3)}$
}

\section{RESUMO}

Chlamydia trachomatis é a bactéria responsável pela doença sexualmente transmissível mais prevalente no mundo. A maioria das infecções em homens e mulheres é assintomática e, quando não diagnosticada e tratada, pode causar artrite e complicações relacionadas ao aparelho reprodutor feminino. Objetivo: pesquisar o DNA de C. trachomatis no líquido sinovial e urina de pacientes com espondiloartropatias e artrite reumatóide (AR), avaliar a presença de anticorpos séricos IgG e IgM anti-C. trachomatis nesses dois grupos de doenças e identificar o antígeno HLA-B27 em pacientes com espondiloartropatias. Métodos: a população do estudo consistiu em 15 pacientes com espondiloartropatias: nove com espondiloartropatia indiferenciada (EI) e seis com artrite reativa (ARe) (grupo I) e 15 pacientes com AR (grupo II). O DNA clamidial foi pesquisado em amostras de líquido sinovial e urina de todos os pacientes, empregando-se a PCR (Amplicor Roche, Suíça). Os anticorpos IgG e IgM anticlamidiais foram quantificados por imunofluorescência indireta (IFI), enquanto o HLA-B27 foi tipado em 15 pacientes do grupo I por citometria de fluxo. Resultados: 0 DNA da C. trachomatis foi evidenciado apenas em uma amostra de líquido sinovial do grupo I (6,7\%), sendo o paciente portador de ARe. Em dois pacientes com AR, o DNA clamidial foi identificado na urina $(13,3 \%)$. Os anticorpos IgG anticlamidiais estavam presentes em oito pacientes da população estudada, três do grupo I (20\%) e cinco do grupo II $(33,3 \%)$. O maior título desse anticorpo (1/256) associou-se com a presença do DNA clamidial na urina de um paciente do grupo II. O anticorpo

\begin{abstract}
Chlamydia trachomatis is the bacteria responsible for the most prevalent sexually transmitted disease worldwide. Most of the infections in men and women is asymptomatic and when undiagnosed and untreated may reach the joints causing not only arthritis, but also other acknowledged complications related to the female reproductive system. Objective: To investigate $C$. trachomatis DNA in the urine and synovial fluid from patients with spondyloarthropathies ( $S p A)$ and rheumatoid arthritis (RA) and evaluate serum anti-C. trachomatis $\operatorname{Ig} G$ and $\operatorname{Ig} M$ antibodies. Methods: The population consisted of 15 patients with spondyloarthropathies, being 9 with undifferentiated spondyloarthropathy (US) and 6 with reactive arthritis (ReA) (group I), and 15 patients with rheumatoid arthritis (RA) (group II). The chlamydial DNA was assessed in synovial fluid and urine samples of all patients by Amplicor (Roche, Swiss) PCR. The antichlamydial $\operatorname{Ig} G$ and $\operatorname{IgM}$ antibodies were quantified through indirect imunofluorescence (IIF), while 15 patients of group I were typed for HLA-B27 by the use of flow citometry. Sociodemographical data and all information on sexual behaviour and presence of symptoms were collected through a (questionnaire in the form of) an interview. Results: C. trachomatis DNA was found in only one synovial fluid sample from patient with ReA (6,7\%). In two patients with RA, chlamydial DNA was identified in the urine sample $(13,3 \%)$. The anti-chlamydial IgG antibodies were present in eight patients of the population studied; being three patients from group I (20\%), and five from group II (33,3\%). The greatest titer of this antibody 1/256 was associated with the
\end{abstract}

* Trabalho realizado na Seção de Reumatologia do Hospital Geral de Goiânia - Dr. Alberto Rassi, Goiânia, GO, Brasil. Este trabalho contou com o apoio do Fundo de Auxílio à Pesquisa e Ensino em Reumatologia da Sociedade Brasileira de Reumatologia. Recebido em 08/03/2005. Aprovado, após revisão, em 20/09/2005.

1. Médico reumatologista do Hospital Geral de Goiânia - Dr. Alberto Rassi, mestre em doenças infecto-parasitárias pela Universidade Federal de Goiás (UFG), Goiânia, GO, Brasil.

2. Doutor em Reumatologia pela Universidade de São Paulo, USP, chefe do Departamento de Medicina Interna do Hospital Geral de Goiânia - Dr. Alberto Rassi, Goiânia, GO, Brasil.

3. Doutora em Imunologia pela USP, coordenadora do Laboratório de Imunologia, IPTSP (Instituto de Patologia Tropical e Saúde Pública), Universidade Federal de Goiás (UFG), Goiânia, GO, Brasil.

Endereço para correspondência: Dr. Rafael Navarrete Fernandez. Rua 9-B, n²23, ap. 1301, Setor Oeste, CEP 74110-120. Goiânia, GO, Brasil. E-mail: navarrete@cultura.com.br 
IgM não foi detectado em nenhuma amostra dos dois grupos. $\mathrm{O}$ antígeno HLA-B27 foi positivo em quatro indivíduos do grupo II $(26,7 \%)$ e sua presença relacionou-se com sacroileíte. Conclusões: os resultados deste estudo indicam que em pacientes com diagnóstico de espondiloartropatias e artrite reumatóide, com quadro articular em atividade, a C. trachomatis não pode ser excluída como agente desencadeador.

Palavras-chave: Chlamydia trachomatis, PCR, espondiloartropatias, artrite reumatóide.

\section{INTRODUÇÃO}

A infecção urogenital por Chlamydia trachomatis é a causa de doença sexualmente transmissível (DST) bacteriana mais prevalente em todo o mundo. Segundo estimativas da Organização Mundial de Saúde, ocorrem a cada ano 4 milhões de novos casos da infecção nos Estados Unidos, 10 milhões na Europa e 92 milhões em todo o mundo ${ }^{(1)}$. No Brasil, existem poucos dados sobre sua prevalência. De acordo com o Ministério da Saúde, em 2001 ocorreram aproximadamente dois milhões de $\operatorname{casos}^{(2)}$. Um estudo em população de adolescentes e jovens do sexo feminino sexualmente ativas demonstrou elevada prevalência $(19,6 \%)$ de infecção genital por C. trachomatis ${ }^{(3)}$. Em outro estudo mais recente, realizado em jovens do sexo masculino assintomáticos que se apresentaram para o serviço militar, a prevalência encontrada foi de $4,9 \%{ }^{(4)}$.

A C. trachomatis é uma bactéria intracelular obrigatória, paratrófica, que possui DNA e RNA ${ }^{(5)}$. Seu ciclo de desenvolvimento tem duas fases. Na primeira, os corpos elementares (CE) extracelulares, metabolicamente inativos e infecciosos, são internalizados por uma célula hospedeira apropriada. Na segunda fase, os CE intracelulares se reorganizam em corpos reticulares (CR), metabolicamente ativos, que se multiplicam por divisão binária. No final dessa fase, os CR já diferenciados em CE são liberados da célula hospedeira via lise para perpetuar a infecção ${ }^{(6,7)}$. A maioria das infecções clamidiais é assintomática, tornando difícil o diagnóstico. O número de homens assintomáticos varia de $25 \%$ a $50 \%$ e de mulheres de $65 \%$ até $90 \%{ }^{(8,9)}$. Sendo assim, a infecção pode induzir complicações onde uma forma persistente deste microrganismo pode estar presente em localizações anatômicas distante do sítio da infecção primária. Em algumas circunstâncias, a clamídia pode se disseminar do trato urogenital para o interior da articulação ou outros locais, como a tuba uterina, causando seqüelas como artrite e infertilidade ${ }^{(10-13)}$.

O diagnóstico da infecção clamidial inclui a cultura, os testes para detecção de antígenos, como a imunofluores- presence of chlamydial DNA in a patient from group II. The IgM antibody was not detected in any of the samples from both groups. Four individuals from group II $(26,7 \%)$ were HLA-B27 positive and its presence was related to sacroiliitis. Conclusions: The results in this study show that in patients with spondyloarthropathies and rheumatoid arthritis, presenting a picture of articular activity, one might not exclude $\mathrm{C}$. trachomatis as the triggering agent

Keywords: Chlamydia trachomatis, PCR, spondyloarthropathies, rheumatoid arthritis.

cência direta (IFD) e o ensaio imunoenzimático (EIA), a pesquisa de anticorpos por imunofluorescência indireta (IFI), ELISA (enzyme linked immunosorbent assay), os testes de detecção de ácidos nucléicos, como a captura híbrida ou hibridização do DNA, e, mais recentemente, os testes de amplificação do DNA, como a reação em cadeia da polimerase (PCR) e a reação em cadeia da ligase ${ }^{(14)}$.

Este método é considerado como o de escolha na pesquisa do DNA clamidial em materiais sinoviais em decorrência da negatividade da cultura e imunofluorescência na maioria das amostras, e pelo baixo número de células bacterianas presentes nas articulações de pacientes com diferentes artrites ${ }^{(15,16)}$.

A presença da clamídia nas articulações foi demonstrada em 1987, por meio de IFD de células presentes no líquido sinovial ${ }^{(17)}$. No ano seguinte, Schumacher et al. ${ }^{(18)}$, com base na microscopia eletrônica de biópsias articulares, reforçaram a hipótese da participação desta bactéria em artropatia inflamatória. Contudo, as tentativas iniciais do uso da PCR para detecção do DNA clamidial apresentaram resultados inconsistentes, como no estudo de Saiki ${ }^{(19)}$ e de outros autores (Wordsworth ${ }^{(20)}$ e Poole ${ }^{(21)}$, incapazes de detectar o DNA da C. trachomatis em biópsias articulares ou líquido sinovial).

Uma contribuição importante para o diagnóstico das espondiloartropatias é a demonstração do microrganismo desencadeador no local da infecção extra-articular primária. No caso da clamídia, a utilização do exame de amostra de urina do primeiro jato em vez de material urogenital pode servir como uma alternativa não-invasiva para a sua demonstração, por meio de métodos de amplificação molecular como a PCR ${ }^{(15)}$.

Branigan et al. ${ }^{(22)}$ levantaram a questão de como a clamídia proveniente do sistema urogenital, o local usual de aquisição da infecção, alcança as articulações. Nesse trabalho, a hibridização in situ e microscopia eletrônica do tecido sinovial mostraram células semelhantes aos 
monócitos contendo inclusões clamidiais. Outros autores apóiam a hipótese de que os monócitos estejam envolvidos nesse transporte ${ }^{(23,24)}$. Os últimos autores detectaram a $C$. trachomatis, por meio de PCR, em leucócitos do sangue periférico de dois pacientes com artrite reativa (ARe). Em um deles o DNA da bactéria também foi encontrado no líquido sinovial, por método de PCR, e no outro a $C$. trachomatis foi cultivada a partir de amostra de swab uretral, reforçando a idéia de que esta bactéria possa se disseminar para as articulações por via hematogênica.

A melhoria dos métodos de rastreamento para clamídia permitiu a identificação de pacientes que possuem antígenos ou ácidos nucléicos clamidiais nas articulações e que não se enquadram nos critérios da EASN. Assim, Zeidler e Wollenhaupt $^{(25)}$, e Wollenhaupt e Zeidler ${ }^{(26)}$ designaram estes casos como artrite associada à clamídia, já que estes pacientes possuem oligoartrite e provavelmente têm mecanismos de doenças semelhantes. Além disso, o DNA de $C$. trachomatis foi encontrado por método de PCR no líquido e tecido sinovial de portadores de artrite reumatóide ${ }^{(27)}$, osteoartrite e em indivíduos assintomáticos estudados como controle ${ }^{(28)}$.

Os dados sobre a associação da C. trachomatis na EASN e AR são contraditórios e existem poucos estudos no mundo que relacionam a AR com a infecção por este microrganismo. No Brasil, até o momento, apenas um estudo avaliou esta associação nestas doenças ${ }^{(29)}$. Considerando a elevada prevalência para a infecção clamidial em jovens e ainda que a maioria das infecções urogenitais por $C$. trachomatis são assintomáticas, fato que induz o médico de várias especialidades a não suspeitar do seu diagnóstico, e assim, não evitar o desenvolvimento de complicações e seqüelas, o presente estudo propôs ampliar os conhecimentos sobre a associação desta infecção nestes dois tipos de artrite inflamatória.

\section{PACIENTES E MÉTODOS}

\section{AMOSTRA}

Entre abril e julho de 2003, foram incluídos no estudo 30 pacientes de ambos os sexos com idade entre 18 e 60 anos, 15 com espondiloartropatias (grupo I) e 15 com artrite reumatóide (grupo II), (Figura 1). Todos os pacientes assinaram o termo de consentimento informado.

\section{CRITÉRIOS DE INCLUSÃO}

- Pacientes de ambos os sexos que preencheram os critérios de diagnóstico de espondiloartropatias e artrite reumatóide em atividade (anexo $\mathrm{V}$ - A a D);
- idade: 18 - 60 anos;

- sem uso de antimicrobianos nos últimos 30 dias;

- ausência de infiltrações articulares com costicoesteróides nos últimos três meses anteriores à consulta.

\section{CRITÉRIOS DE EXCLUSÃO}

- Pacientes que não preencheram os critérios diagnósticos de espondiloartropatias e artrite reumatóide (anexo V - A a D);

- gestantes;

- no grupo I, diarréia nos últimos 30 dias anteriores à consulta;

- presença de líquido sinovial purulento tipo III, considerado séptico:

- cor: esverdeado ou esbranquiçado;

- aspecto: turvo;

- viscosidade: baixa;

- coágulo espontâneo: presente;

- contagem celular: $>50.000 / \mathrm{mm}^{3}$, com predomínio de polimorfonucleares (+ de $80 \%$ );

- cristais: ausentes;

- glicose: abaixo de 30mg;

- microrganismos: presente.

\section{Coleta das amostras}

Durante a consulta o paciente foi convidado a participar da pesquisa, após ter sido esclarecido que se submeteria a uma avaliação médica e que seriam coletadas amostras de sangue, urina e punção articular (artrocentese). A artrocentese foi realizada no joelho, segundo as normas preconizadas por Gater ${ }^{(30)}$, obedecendo-se métodos rigorosos de assepsia e anti-sepsia e uso de agulha adequada para o tamanho da articulação acometida. Para a coleta do líquido sinovial foi utilizada a técnica de anestesia com injeção subcutânea de xilocaína $2 \%$ sem vasoconstritor. O líquido sinovial foi coletado em três tubos, dois contendo anticoagulante (EDTA) e um sem anticoagulante. Em cada tubo foram adicionados pelo menos $3 \mathrm{ml} \mathrm{da}$ amostra. Dois tubos foram enviados para laboratório especializado na realização da citologia sinovial com citometria, exame bioquímico (glicose, proteínas), citometria qualitativa e quantitativa e pesquisa do fator reumatóide. Também foi realizada a cultura para bactérias anaeróbicas, aeróbicas e fungos, além da bacterioscopia (Ziehl-Neelsen e BAAR).

Foram coletados em recipiente estéril $10 \mathrm{ml}$ de urina do $1^{\circ}$ jato, com um intervalo de no mínimo duas horas entre a última micção e a coleta, que juntamente com uma 


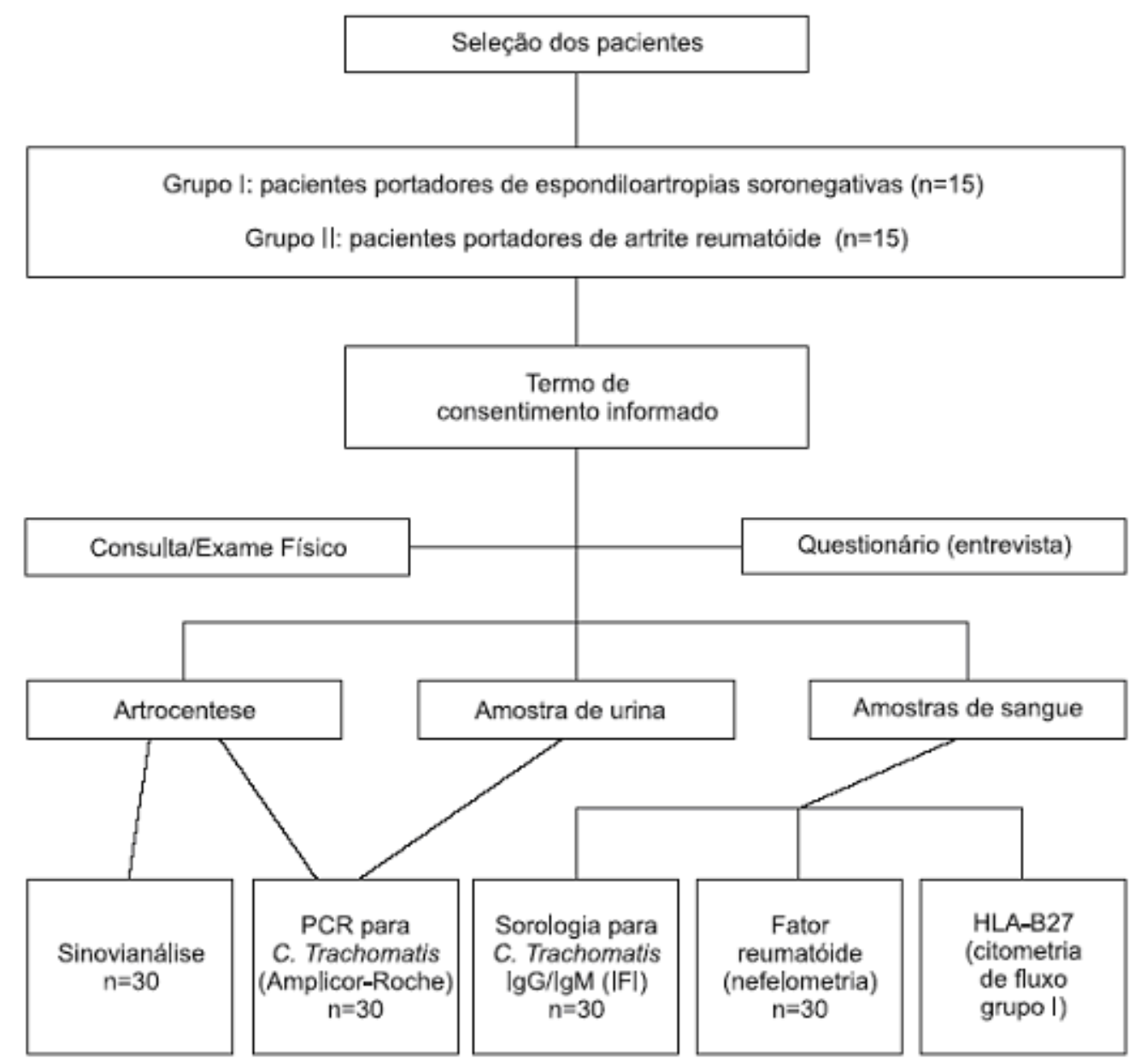

FigURA 1 - Fluxograma do presente estudo

amostra do líquido sinovial contendo EDTA, foram encaminhadas, em recipiente refrigerado, para o Laboratório de Imunologia Celular do Instituto de Patologia Tropical e Saúde Pública da Universidade Federal de Goiás (IPTSP/UFG), para a pesquisa do DNA de C. trachomatis.

Também foram coletados $10 \mathrm{ml}$ de sangue periférico, $5 \mathrm{ml}$ em tubo contendo anticoagulante ACD (ácido cítrico, citrato de sódio e dextrose) para a realização da tipagem do antígeno HLA-B27 e $5 \mathrm{ml}$ em tubo sem anticoagulante para a realização da sorologia para $C$. trachomatis e a pesquisa do fator reumatóide.

\section{PCR PARA C. TRACHOMATIS}

A PCR foi realizada no líquido sinovial e na urina empregando-se o kit CT/NG Amplicor/Roche (Suíça) que utiliza os primers CP24 e CP27 para definir uma seqüência de aproximadamente 207 nucleotídeos dentro do plasmídio críptico da C. trachomatis. Os procedimentos laboratoriais seguiram as instruções do fabricante indicadas para a análise de amostras de urina. Após a coleta das amostras (líquido sinovial e urina), estas foram separadas em alíquotas e armazenadas a $-80^{\circ} \mathrm{C}$ até o processamento. A seguir, $50 \mu \mathrm{l}$ da amostra processada contendo DNA, juntamente com 
$50 \mu \mathrm{l}$ de Master Mix foram transferidos para o tubo de reação. As amplificações foram feitas em termociclador Perkin-Elmer GeneAmp PCR System 2400. Os controles positivos e negativos, fornecidos pelo kit, além do controle interno do teste (CI), foram incluídos em cada série de testes realizados. A falha na detecção do CI após a amplificação indica a presença de alguma substância inibidora da enzima Taq DNA polimerase na amostra.

\section{Pesquisa de anticorpos igm e igg anti-C. TRACHOMATIS}

A sorologia foi realizada por imunofluorescência indireta (IFI), empregando o kit Chlamydia trachomatis - Spot IF (bioMérieux, França) de acordo com as instruções do fabricante. As amostras foram colocadas em uma lâmina com o substrato de C. trachomatis (sorovariedade L2). Os anticorpos anti-C. trachomatis fixados ao antígeno foram revelados por uma globulina anti-humana apropriada marcada com fluoresceína. Foram consideradas como positivas as amostras com títulos para $\operatorname{IgG} \geq 1 / 16$ e $\operatorname{Ig} M \geq 1 / 8$.

\section{Pesquisa do antígeno HLA-B27}

A tipagem do HLA-B27 foi realizada nos 15 pacientes com EASN por meio de citometria de fluxo. Os anticorpos monoclonais anti-HLA-B27 e anti-HLA-B7 foram fornecidos pela Immunotech (Marseille, França) e para a leitura foi empregado o citômetro de fluxo (FACScan, Becton Dickinson - EUA).

\section{DOSAGEM DO FATOR REUMATÓIDE}

O fator reumatóide foi quantificado por meio de nefelometria utilizando o kit Rheumatoid Factor (Beckman Coulter - USA), considerando como valores de referência para sua positividade títulos $\geq 20 \mathrm{UI} / \mathrm{ml}$. Os testes foram realizados em nefelômetro Array 360 (Beckman Coulter - EUA).

\section{Aspectos ÉtICOS}

Este estudo foi aprovado pelo Comitê de Ética em Pesquisa Humana e Animal. Os pacientes que apresentaram PCR positiva para C. trachomatis foram tratados com doxiciclina $200 \mathrm{mg} /$ dia por quatro semanas.

\section{ANÁLISE DOS DADOS}

O processamento e análise dos dados foram realizados usando o programa Epi-Info (versão 6.0 e 2000). Foi feita a análise descritiva de todas as variáveis, por meio da distribuição de freqüência e cálculos das médias, quando pertinentes. A presença de anticorpos IgG anticlamidiais foi comparada nos dois grupos estudados por meio do teste do $\chi^{2}$. A média de idade entre os dois grupos foi comparada empregando-se o teste $\mathrm{t}$ de Student.

\section{RESULTADOS}

\section{CARACTERÍSTICAS DOS PACIENTES ESTUDADOS}

Dados sócio-demográficos

O grupo I foi constituído por 15 pacientes portadores de espondiloartropatias, sendo 9 classificados como espondilite anquilosante (EA) e 6 como artrite reativa (ARe). O grupo II foi composto por 15 pacientes portadores de artrite reumatóide. O tempo de duração da doença no grupo I variou de 7 dias a 8 meses, enquanto no grupo II a variação foi de 6 meses a 23 anos. A média de idade $( \pm$ DP) do grupo I foi de 37,6 $\pm 2,6$ anos, enquanto a do grupo II foi de 42,7 $\pm 3,2$ anos, sem diferença estatisticamente significativa entre os dois grupos $(\mathrm{p}>0,05)$.

$\mathrm{O}$ sexo feminino predominou igualmente nos dois grupos (73,5\%). Dos 15 pacientes do grupo I, a maioria era casada ou vivia em união consensual (80,5\%); o mesmo foi observado no grupo II $(53,3 \%)$. Quatro pacientes do grupo I $(26,7 \%)$ tinham curso superior completo ou incompleto. Um terço dos pacientes do grupo II cursou até a $4^{\text {a }}$ série do $1^{\circ}$ grau (Tabela 1).

TABELA 1

CARACTERÍSTICAS SÓCIO-DEMOGRÁFICAS E DE COMPORTAMENTO SEXUAL DOS PACIENTES COM ESPONDILOARTROPATIAS (GRUPO I, N=15) E DOS PACIENTES COM ARTRITE REUMATÓIDE (GRUPO II, N=15)

\begin{tabular}{|c|c|c|}
\hline Variável & $\begin{array}{c}\text { Grupo I } \\
\text { n (\%) }\end{array}$ & $\begin{array}{c}\text { Grupo II } \\
\text { n (\%) }\end{array}$ \\
\hline \multicolumn{3}{|l|}{ Idade (anos) } \\
\hline $18-24$ & $02(13,4)$ & $02(13,4)$ \\
\hline $25-40$ & $05(33,3)$ & $04(26,7)$ \\
\hline $41-60$ & $08(53,3)$ & $09(60,0)$ \\
\hline \multicolumn{3}{|l|}{ Sexo } \\
\hline Feminino & $11(73,3)$ & $11(73,3)$ \\
\hline Masculino & $04(26,7)$ & $04(26,7)$ \\
\hline \multicolumn{3}{|l|}{ Estado civil } \\
\hline Casado/união consensual & $12(80,0)$ & $08(53,3)$ \\
\hline Solteiro & $03(20,0)$ & $07(43,7)$ \\
\hline \multicolumn{3}{|l|}{ Grau de escolaridade (anos) } \\
\hline$<5$ & $02(13,3)$ & $05(33,3)$ \\
\hline $5-8$ & $05(33,3)$ & $03(20,0)$ \\
\hline $9-11$ & $04(26,7)$ & $06(40,0)$ \\
\hline$>11$ & $04(26,7)$ & $01(06,7)$ \\
\hline \multicolumn{3}{|l|}{ Duração da doença } \\
\hline Dias $(7-30)$ & $05(33,3)$ & - \\
\hline Meses $(2-10)$ & $10(66,7)$ & $04(26,7)$ \\
\hline Ano(s) (1-23) & - & $11(73,3)$ \\
\hline
\end{tabular}




\section{Acometimento articular}

Oitenta por cento dos pacientes $(12 / 15)$ do grupo I tiveram oligoartrite como apresentação articular, enquanto no grupo II, $100 \%$ dos pacientes apresentaram poliartrite.

Os joelhos estavam acometidos em todos os pacientes dos dois grupos, seguidos dos tornozelos. Quatro pacientes do grupo I $(26,7 \%)$ apresentaram comprometimento radiológico das articulações sacroilíacas e três $(20,0 \%)$ de calcâneos (entesopatia) (Tabela 2). Dos quatro pacientes que apresentaram sacroileíte, três tiveram envolvimento unilateral e um bilateral. O diagnóstico de EA nestes pacientes não se confirmou por falta de critérios.

\section{Manifestações extra-articulares}

Dois pacientes do grupo I (13,4\%) tiveram como comprometimento ocular, uveíte anterior, enquanto um do grupo II $(6,7 \%)$ apresentou antecedente de episclerite. Quadro de cervicite esteve presente em sete pacientes do grupo I $(46,7 \%)$ e manifestou-se antes do início do quadro articular. No grupo II, uma paciente $(6,7 \%)$ também relatou cervicite antes do início do comprometimento articular e dois pacientes apresentaram nódulos subcutâneos. Todos os pacientes do grupo II com manifestações extra-articulares tinham fator reumatóide positivo $(66,7 \%)$.

\section{RESULTADOS DA PCR PARA C. TRACHOMATIS}

O DNA da C. trachomatis foi detectado em uma amostra (A2) do líquido sinovial do grupo I $(6,7 \%)$ e em duas amostras (A16 e A17) de urina do grupo II (13,3\%). Um dos pacientes (A16), apresentou título elevado de anticorpos IgG anticlamidiais (1/256). Contudo, isso não ocorreu nos outros pacientes com PCR positiva para C. trachomatis (Tabela 3).

A inibição da PCR, evidenciada pelo uso do CI, foi observada em apenas três $(10,0 \%)$ das 30 amostras de líquido sinovial e todas elas eram de pacientes portadores de artrite reumatóide. Em nenhuma das amostras de urina ocorreu inibição. Após diluição a 1/10 e nova amplificação, todas as amostras que haviam apresentado inibição na PCR foram negativas para o DNA de C. trachomatis e amplificaram adequadamente o CI da reação.

\section{AVALIAÇÃo dE ANTICORPOS IGG E IGM ANTICLAMIDIAIS POR MEIO DE IFI}

Os anticorpos IgG anticlamidiais foram detectados em três amostras do grupo I $(20,0 \%)$ e em cinco do grupo II $(33,3 \%)$, sem diferença estatisticamente significativa entre os dois grupos. Os títulos de anticorpos $\mathrm{IgG}$ no grupo I variaram de $1 / 32$ a 1/128, enquanto no grupo II a variação
TABELA 2

ARTICULAÇÕES ACOMETIDAS EM PACIENTES COM ESPONDILOARTROPATIAS (GRUPO I, N=15) E ARTRITE ReUmATÓide (GRUPO II, N=15)

\begin{tabular}{lcc}
\hline Articulações & $\begin{array}{c}\text { Grupo I } \\
\text { n (\%) }\end{array}$ & $\begin{array}{c}\text { Grupo II } \\
\text { n (\%) }\end{array}$ \\
\hline Joelho(s) & $15(100,0)$ & $15(100,0)$ \\
\hline Tornozelo(s) $^{(a)}$ & $12(80,0)$ & $14(93,3)$ \\
\hline Pé(s) & $01(6,7)$ & $10(66,7)$ \\
\hline Mão(s) & $01(6,7)$ & $12(80,0)$ \\
\hline Punho(s) & $01(6,7)$ & $13(86,7)$ \\
Coluna lombar & $04(26,7)$ & - \\
Coluna cervical & - & $02(13,4)$ \\
Sacroilíaca(s) ${ }^{(a)}$ & $04(26,7)$ & - \\
Ombro(s) & - & $07(46,7)$ \\
Cotovelo(s) & - & $05(33,3)$ \\
Quadril(s) & $02(13,4)$ & $05(33,3)$ \\
Entesopatia & $03(20,0)$ & - \\
\hline Temporomandibular(es) & - & $01(6,7)$ \\
\hline (a) confirmado radiologicamente & &
\end{tabular}

foi de $1 / 16$ a 1/256. Oitenta por cento desses anticorpos estavam presentes em pacientes do sexo feminino. A pesquisa dos anticorpos IgM anticlamidiais foi negativa em todos os pacientes dos dois grupos (Tabela 3).

\section{ANTÍGENO HLA-B27}

O HLA-B27 foi pesquisado somente no grupo das espondiloartropatias. Dos 15 pacientes, quatro foram positivos para esse antígeno $(26,7 \%)$, três deles foram classificados como EI $(3 / 9$ - 33,3\%) e um como ARe (1/6 - 16,6\%) (Tabela 3). Nenhum dos quatro pacientes apresentava anticorpos anticlamidiais. Todos eles tinham comprometimento das articulações sacroilíacas (100,0\%), dois entesopatia de calcâneos $(50,0 \%)$ e um história prévia de uveíte anterior $(25,0 \%)$.

\section{FATOR REUMATÓIDE}

O fator reumatóide foi quantificado em toda a população do estudo. Dos 15 pacientes do grupo II, oito $(53,3 \%)$ foram positivos no soro em títulos que variaram de 23 a $413 \mathrm{UI} / \mathrm{ml}$ (Tabela 3). Este marcador não estava presente no soro de pacientes do grupo I.

\section{ANÁLISE DO LÍQUIDO SINOVIAL}

As 30 amostras de líquido sinovial apresentaram resultados negativos na pesquisa de cristais, bem como na bacterios- 


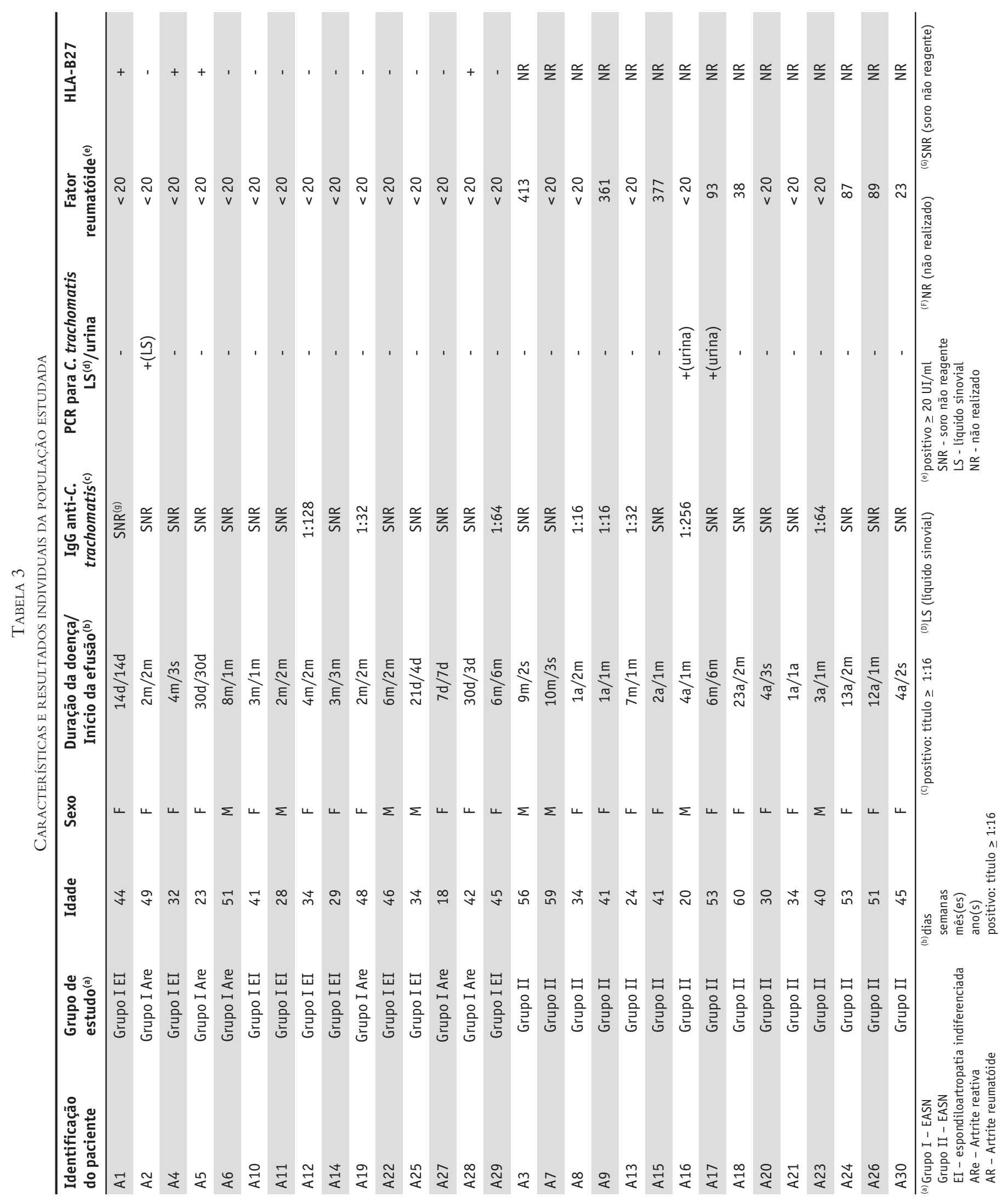


copia (Gram, BAAR) e culturas (germes inespecíficos, gonococos, Mycobacterium tuberculosis e fungos). No grupo I, os leucócitos variaram de 270 a 15.680/ $\mu$ l, com

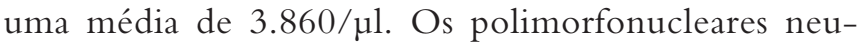
trófilos de 0 a $90,0 \%$, com uma média de $45,2 \%$. No grupo II, os leucócitos variaram de 1.040 a $24.000 / \mu l$, com uma média de $6.412 / \mu 1$. Os polimorfonucleares neutrófilos de $5,0 \%$ a $90 \%$, média de $65,5 \%$. O tipo predominante para o líquido sinovial nos dois grupos foi o inflamatório (tipo II).

\section{DISCUSSÃo}

Os estudos que envolvem a associação entre C. trachomatis e artrite apresentam resultados conflitantes. Neste trabalho foram avaliadas duas modalidades de artropatia inflamatória. O grupo I foi composto de pacientes portadores de espondiloartropatias, cuja relação causal com a C. trachomatis é mais bem documentada e o grupo II constituído por pacientes com artrite reumatóide, onde o papel da $C$. trachomatis ainda não foi estabelecido.

No presente estudo, a pesquisa de C. trachomatis foi realizada, no líquido sinovial e na urina, empregando-se a PCR, teste que amplifica o DNA plasmidial e que apresenta alta sensibilidade e especificidade ${ }^{(14,31)}$. O DNA foi evidenciado apenas em uma amostra de líquido sinovial do grupo I, de um paciente com ARe (6,7\%). Resultado semelhante ao de Kuipers et al. ${ }^{(24)}$, que também utilizaram a PCR Amplicor/Roche e encontraram uma amostra positiva, em 21 análises de pacientes com a mesma doença $(4,8 \%)$. Nesse mesmo estudo, os autores obtiveram apenas dois resultados positivos para o DNA clamidial em 79 pacientes com EI $(2,5 \%)$. Contudo, Nikkari et al. ${ }^{(32)}$, empregando a mesma técnica de DNA, não encontraram nenhuma amostra positiva para C. trachomatis no líquido sinovial de 12 pacientes com ARe.

Esse resultado está de acordo com o de outros estudos, como o de Wordsworth et al. ${ }^{(20)}$, que também não detectaram o DNA plasmidial, empregando PCR desenvolvida pelos autores, em nove articulações de pacientes com ARe. Alguns pesquisadores que realizaram PCR no líquido sinovial, tendo como alvo o DNA da MOMP, também não obtiveram resultado positivo em pacientes com Are ${ }^{(21,29)}$.

Segundo a literatura, a não detecção do DNA de $C$. trachomatis no líquido sinovial de pacientes com artrite reativa pode ser explicada por várias hipóteses: a) a resposta inflamatória pode ocorrer na ausência da clamídia na articulação; b) a bactéria pode estar presente em quantidades inferiores à sensibilidade da reação utilizada. A escolha de novos primers que amplifiquem regiões diferentes do DNA da C. trachomatis pode ser utilizada como uma estratégia para se aumentar a sensibilidade do método; c) é possível que a bactéria se encontre mais localizada no tecido do que no líquido sinovial; d) a clamídia intra-articular pode perder plasmídios e também o gene da MOMP em conseqüência do tratamento com antimicrobianos; e) a bactéria intacta pode se desintegrar rapidamente antes do estabelecimento da artrite, podendo não ser mais detectada a partir da quarta semana da infecção primária (15,19-22,29,30,33-36).

A presença de inibidores da enzima Taq DNA polimerase em amostras de líquido sinovial e de urina também pode ser um fator responsável pelos resultados negativos da PCR; em nosso estudo, porém, esta hipótese foi descartada, pois foi empregado o controle interno do teste, que revela a presença de inibidores da PCR na amostra ${ }^{(37,38)}$. A inibição ocorreu em apenas três amostras de líquido sinovial, desaparecendo ao serem diluídas a $1 / 10$ e submetidas à nova amplificação, como sugerido por Mahony ${ }^{(39)}$ para amostras de urina. Assim, todas as amostras testadas novamente foram negativas para C. trachomatis e amplificaram adequadamente o CI da reação de PCR. Um aspecto interessante dessa observação foi que as três amostras do líquido sinovial eram de pacientes portadores de artrite reumatóide, o que sugere que o líquido sinovial destes pacientes possa apresentar maior quantidade de inibidores.

Por outro lado, vários autores que também pesquisaram a presença de ácidos nucléicos da C. trachomatis no líquido sinovial de pacientes com EI e ARe obtiveram porcentuais de positividade bem superiores aos encontrados no presente estudo, que variaram de $17,3 \%$ a $60 \%$, seja para o DNA plasmidial ${ }^{(40)}$, para o gene da MOMP ${ }^{(24,36,41)}$ ou ainda para o RNA ribossomal ${ }^{(16,42)}$. Uma justificativa para a grande variabilidade nos resultados da PCR é que não existe, até o presente momento, padronização nas técnicas de amplificação de ácidos nucléicos clamidiais pelos grupos que estudam o envolvimento da clamídia com artrites inflamatórias, ou seja, cada laboratório adota seu próprio método de extração do DNA, amplificação e detecção (uso da PCR in house, kits comerciais), que varia amplamente entre os grupos de pesquisa ${ }^{(43)}$.

Neste estudo, o DNA da C. trachomatis foi detectado em duas amostras de urina de pacientes com $\operatorname{AR}(13,3 \%)$, dados que diferem dos de Schnarr ${ }^{(41)}$. Esses autores não observaram nenhuma urina positiva, em pacientes com AR, empregando a técnica de LCR, que também amplifica o DNA clamidial. Nesse mesmo estudo, quando a PCR foi realizada no líquido sinovial e direcionada para um alvo 
diferente (MOMP), também foi negativa em todos os pacientes. Esses resultados coincidem com os de outros autores que também pesquisaram o DNA da MOMP no líquido sinovial de pacientes com $\operatorname{AR}^{(29)}$.

Em outros trabalhos realizados em pacientes com AR, alguns autores conseguiram detectar o DNA da C. trachomatis no líquido sinovial, empregando como alvo o gene 16s do rRNA. As taxas de prevalência encontradas foram 38,8\% $(7 / 18 \text { amostras })^{(16)}$ e 14,3\% (3/21 amostras). Os últimos autores também evidenciaram o DNA clamidial no tecido sinovial $(24,0 \%)$.

No presente estudo, os anticorpos séricos IgG e IgM anticlamidiais foram detectados e quantificados utilizandose a técnica de IFI. Os anticorpos da classe IgM não foram encontrados em nenhuma das amostras de ambos os grupos. Os anticorpos IgG foram detectados em 20,0\% dos pacientes do grupo I e em 33,3\% do grupo II, sem diferença estatisticamente significativa quanto à positividade entre os dois grupos. Resultados semelhantes foram encontrados por outros autores em pacientes com EI $(22 \%$ e $25,8 \%$, respectivamente) ${ }^{(42,45)}$.

Entretanto, Bas et al. ${ }^{(46)}$, pesquisando anticorpos $\operatorname{IgG}$ e IgM anticlamidiais no soro e no líquido sinovial, em uma população de 26 portadores de EI, encontraram um porcentual menor de positividade (de aproximadamente 15\%), tanto para anticorpos da classe IgG quanto IgM. Não houve discrepância quanto à detecção dos anticorpos no soro e no líquido sinovial. Por outro lado, taxas maiores de positividade foram encontradas por Bas e Vischer ${ }^{(47)}$ ao avaliarem um grupo de 30 pacientes com EI. Naquela população, empregando o teste de ELISA, a positividade para IgG antiLPS foi de $63 \%$ e para IgG anti-MOMP foi de $17 \%$. Ximenes $^{(48)}$, em um estudo com 40 pacientes com Are, detectaram anticorpos IgG anti-C. trachomatis em 34,7\% e IgM em 13,0\%. Nikkari et al. ${ }^{(32)}$ encontraram taxas elevadas de anticorpos IgG anti-C. trachomatis $(83,0 \%-19$ / 23) em pacientes com Are induzidos por C. trachomatis e que apresentavam cultura ou antígenos positivos. Em pacientes com AR estes mesmos autores mostraram positividade para IgG anti-C. trachomatis de 32,0\% - 8/23, resultados semelhantes aos deste trabalho. No presente estudo, assim como no de Wilkinson et al. ${ }^{(42)}$, não foi possível estabelecer correlação entre a presença de anticorpos e a detecção do DNA, em razão do pequeno número de pacientes com PCR positiva.

O valor da detecção de anticorpos anticlamidiais no diagnóstico da EI e ARe é controverso, porque esses anticorpos são freqüentes na população em geral ${ }^{(44,46,49)}$.
Uma explicação para isto é que na infecção genital por $C$. trachomatis, após a soroconversão, os títulos de anticorpos IgG alcançam seu pico em algumas semanas e podem persistir por anos, mesmo após o tratamento efetivo, ou decrescerem lentamente, dependendo da sensibilidade do teste sorológico empregado ${ }^{(50)}$.

O antígeno HLA-B27 é considerado como um marcador genético associado às espondiloartropatias. Sua incidência varia de acordo com a metodologia empregada (microcitotoxicidade, citometria de fluxo ou PCR), com a população estudada (peruanos 1,1\%) ${ }^{(51)}$ e com o tipo de doença (por exemplo: $95 \%$ em caucasianos com espondilite anquilosante) ${ }^{(52)}$. Neste estudo, a positividade para o HLA-B27 no grupo das espondiloartropatias foi de 26,7\% (4/15). Três pacientes apresentaram EI $(3 / 9-33,3 \%)$ e um tinha ARe $(1 / 6-16,6 \%)$. Prevalência menor para este marcador foi encontrada por Bas et al. ${ }^{(36)}$, que avaliaram 14 pacientes com EI e o HLA-B27 foi identificado em apenas dois deles $(14,3 \%)$. Por outro lado, um índice maior foi observado por Sampaio Barros et al. ${ }^{(53)}$, que, num grupo de 54 pacientes com esta mesma doença, obtiveram 54\% de positividade para este antígeno. $\mathrm{Na}$ ARe, a comparação de nossos resultados com os de outros estudos também mostra variação: em um estudo de Cuchacovich et al. ${ }^{(54)}$, utilizando a técnica de microcitotoxicidade, somente um $(6,7 \%)$ em 15 pacientes apresentou HLA-B27 positivo. Por outro lado, Poole et al. ${ }^{(21)}$ encontraram este antígeno em 12 de 17 indivíduos (70,5\%).

Os quatro pacientes que no presente estudo expressavam o HLA-B27 tiveram comprometimento das articulações sacroilíacas $(100,0 \%)$. Destes, três apresentaram entesopatia de calcâneos $(66,7 \%)$ e um história prévia de uveíte anterior $(25,0 \%)$. Estes dados estão de acordo com o trabalho de Sieper e Kingsley ${ }^{(55)}$, que sugeriram que o HLA-B27 está mais associado com sacroiléte e entesopatias do que com sinovite. Observações confirmadas por Leirisalo-Repo e Suoranta ${ }^{(56)}$ em pacientes com envolvimento das articulações sacroilíacas, mas não com artrite periférica, induzida por Yersinia.

No presente estudo, nenhum paciente com positividade para o antígeno HLA-B27 apresentou o DNA de C. trachomatis pela PCR. Resultados similares aos de Wilkinson et $a l^{(42)}$, que não observaram esta correlação no líquido sinovial de pacientes com EI e também Cuchacovich et al. ${ }^{(54)}$ na ARe. Todavia, Bas et al. ${ }^{(36)}$, pesquisando 27 indivíduos com EI, encontraram o DNA bacteriano no líquido sinovial de dois pacientes $(7,4 \%)$ e o HLA-B27 estava presente em um deles. 
Esta é a primeira pesquisa realizada no Brasil envolvendo a detecção do DNA plasmidial da C. trachomatis, no líquido sinovial e urina, em pacientes com doenças artritogênicas como as espondiloartropatias e AR. Uma possível limitação do estudo foi o uso de uma única técnica de PCR, embora seja considerada pela literatura como a mais sensível, tanto para amostras endocervicais e uretrais ${ }^{(57,58)}$, como para amostras de líquido sinovial ${ }^{(36)}$. A amplificação do DNA cromossomal (como o gene da MOMP, por exemplo) ou do RNA ribossomal poderia aumentar a positividade para $C$. trachomatis, na população estudada.

\section{REFERÊNCIAS ${ }^{(1)}$}

1. World Health Organization - WHO: Department of Communicable Disease Surveillance and Response. Global prevalence and incidence of selected curable sexually transmitted infections. 1-42. http:// www.who.int/emc. 2001.

2. Ministério da Saúde - MS. Boletim do Ministério da Saúde. http:// www.saude.gov. 2002.

3. Araújo RSC: Estudo da infecção genital por Chlamydia trachomatis em adolescentes e jovens do sexo feminino no distrito sanitário leste do município de Goiânia: prevalência e fatores de risco (Mestrado). Goiânia: Universidade Federal de Goiás. p. 49, 2001.

4. Fioravante FCR: Estudo da prevalência e dos fatores de risco associados à infecção por Chlamydia trachomatis em conscritos do Exército no Município de Goiânia, Goiás. (Mestrado). Goiânia: Universidade Federal de Goiás; 45 p., 2003.

5. Guaschino S, De Seta F: Update on Chlamydia trachomatis. Ann N Y Acad Sci 900: 293-300, 2000.

6. Wyrick P, Stephens RS, Byrne GI, et al (Eds): Cell biology of Chlamydia infection: a journey in the host epithelial cell by the ultimate cellular microbiologist. International Chlamydia Symposium, San Francisco: Chlamydia Infections; p. 69-78, 1998.

7. Hackstadt T: Chlamydia Intracellular Biology, Pathogenesis, and Immunity. American Society for Microbiology. Washington DC; p. 101-38, 1999.

8. Centers for Disease Control and Prevention. Chlamydia (STD). Some Facts about Chlamydia. April 2000. http://www.cdc.gov/ health/ diseases.htm, 2000 .

9. Nelson HD, Helfand M: Screening for clamidial infection. Am J Prev Med 20: 95-107, 2001.

10. Pavoneen J, Eggert-Kruse W: Chlamydia trachomatis: impact on human reproduction. Human Reproduction Update 5: 433-47, 1999.

11. Beatty WL, Morrison RP, Byrne GI: Persistent Chlamydia: from cell culture to a paradigm for Chlamydial pathogenesis. Rev Microbiol 58: 686-99, 1994.

12. Nanagara R, Li F, Beutler AM, Hudson AP, Schumacher HR: Alteration of Chlamydia trachomatis biological behavior in synovial membranes: suppression of surface antigen production in reactive arthritis and Reiter's syndrome. Arthritis Rheum 38: 1410-7, 1995.

13. Inman RD, Whittum-Hudson JA, Schumacher HR, Hudson AP: Chlamydia-associated arthritis. Curr Opin Rheumatol 12: 254-62, 2000 .

14. Centers for Disease Control and Prevention 2002. Screening Tests To Detect Chlamydia trachomatis and Neisseria gonorrhoeae Infections. Morbidity and Mortality Weekly Report 51: 1-48, 2002.

15. Taylor-Robinson D, Gilroy CB, Thomas BJ, Keat ACS: Detection of Chlamydia trachomatis DNA in joints of reactive e arthritis patients by polymerase chain reaction. Lancet 340: 81-2, 1992.

16. Wilkinson NZ, Kingsley GH, Jones HW, Sieper J, Braun J, Ward ME: Detection of DNA from a range of bacterial species in the joints of patients with a variety of arthritides using a nested, broadrange polymerase chain reaction. Rheumatol 38: 260-6, 1999.

17. Keat A, Thomas B, Dixey J, Osborn M, Sonnex C, Taylor-Robinson D: Chlamydia trachomatis and reactive arthritis: the missing link. Lancet : 72-4, 1987.

18. Schumacher HR Jr, Magge S, Cherian PV, et al: Ligth and electron microscopic studies on the sinovial membrane in Reiter's syndrome immunocytochemical identification of chlamydial antigen in patients with early disease. Arthritis Rheum 31: 937-46, 1988.

19. Saiki RK, Gelfand DH, Stoffel S, et al: Primer-directed enzymatic amplification of DNA with a thermostable DNA polymerase. Science 239: 487-91, 1988.

20. Wordsworth BP, Hughes RA, Allan I, Keat AC, Bell JI: Chlamydial DNA is absent from the joints of patients with sexually acquired reactive arthritis. Br J Rheumatol 29: 208-10, 1990.

21. Poole ES, Highton J, Wilkins RJ, Lamont IL: A search for Chlamydia trachomatis in sinovial fluids from patients with reactive arthritis using the polymerase chain reaction and antigen detection methods. Br J Rheumatol 31: 31-4, 1992.

22. Branigan PJ, Gerard HC, Hudson AP, Schumacher HJ: Comparison of sinovial tissue and sinovial fluid as the source of nucleic acids for detection of Chlamydia trachomatis by polymerase chain reaction. Arthritis \& Rheumatism. American College of Rheumatology 39: 1740-6, 1996.

23. Koehler L, Nettelnbreker E, Ott N, Drommer W, Zeidler H: Persistent non-productive infection of human peripheral monocytes with Chlamydia trachomatis serovar $\mathrm{K}$ is due to an intracellular growth arrest at an early stage of chlamydial development. In, Chlamydial infections. Edited by J Orfila, GI Byrne, MA Chernesky, et al. Soc Ed Escul. 1994.

24. Kuipers JG, Andresen J, Köhler L, et al: Evaluation of Amplicor® Chlamydia PCR and LCX® Chlamydia LCR to detect Chlamydia trachomatis in synovial fluid. Clin Exper Rheumatol 20: 185-92, 2002.

25. Zeidler H, Wollenhaupt J: Chlamydia-induced arthritis: the clinical spectrum, serology, and prognosis. In: HLA-B27 Spondyloarthopathies. Edited by Lipsy PE, Taurog JD. New York: Elsevier 175-87, 1991.

26. Wollenhaupt J, Zeidler $H$. Undifferentiated arthritis and reactive arthritis. Curr Opin Rheumatol 10: 306-13, 1998.

27. Rahman MU, Hudson AP, Schumacher HR Jr: Chlamydia and Reiter's syndrome (reactive arthritis). Rheum Dis North Am 18: 67-79, 1992b.

28. Schumacher HR, Arayssi T, Crane M, et al: Chlamydia trachomatis nucleic acids can be found in synovium of some asymptomatic volunteers. Arthritis Rheum 42: 1281-4, 1999. 
29. Detanico T, Sabrito AC, Keirseman M, Chies JAB, Bonorino C: Um modelo para estudo da imunomodulação em pacientes com artrite reativa. Rev Bras Reumatol 42: 277-84, 2002.

30. Gater R. American College of Rheumatology guidelines of performing office sinovial fluid examinations. J Clin Rheumatol 1: 194-9, 1995.

31. Black MC: Current methods of laboratory diagnosis of Chlamydia trachomatis infections. Rev Clin Microbiol 10: 160-84, 1997.

32. Nikkari S, Puolakkainen M, Yli-Kerttula U, Lukkainen R, Toivanen $\mathrm{P}$, Lehtones OP: Ligase Chain reaction in detection of Chlamydia DNA in sinovial fluid cells. Br J Rheumatol 36: 763-5, 1997.

33. Ford DK, Reid GD, Magge S, Schumacher HR: Synovial Lymphocyte response to chlamydial Stimulation associated with intrasynovial chlamydial antigen in a patient with "rheumatoid arthritis". Arthritis Rheum 31: 915-7, 1988.

34. An Q, Radcliffe G, Vassalo R, et al: Infection with a plasmid-free variant Chlamydia related to Chlamydia trachomatis identified using multiple assays for nucleic acid detection. J Clin Microbiol 30: 2814-21, 1992.

35. An Q, Olive M: Molecular cloning and nucleic acid sequencing of Chlamydia trachomatis $16 \mathrm{~S}$ rRNA genes from patients samples lacking the cryptic plasmid. Mol Cell Probes 8: 429-35, 1994.

36. Bas S, Griffais R, Kvien TK, Glennas A, Melby K, Vischer TL: Amplification of plasmid and chromosome Chlamydia DNA sinovial fluid of patients with reactive arthritis and undifferentiated seronegative oligoarthropathies. Arthritis Rheum 38: 1005-13, 1995.

37. Bassiri M, Mardh P-A, Domeika M: The European Chlamydia Epidemiology Group; Multiplex AMPLICOR PCR screening for Chlamydia trachomatis and Neisseria gonorrhoeae in women attending non-sexually transmitted disease clinics. J Clin Microbiol 35: 2556-60, 1997.

38. Rosenstraus M, Wang Z, Chang S-Y, Debonville D, Spadoro JP: An internal control for routine diagnostic PCR: design, properties, and effect on clinical performance. J Clin Microbiol 36: 191-7, 1998.

39. Mahony J, Chong S, Jang D, et al: Unine speciments from pregnant and nonpregnant women inhibitory to amplification of Chlamydia Trachomatis nucleic acid by PCR, ligase chain reaction, and transcription-mediated amplification: identification of urinary substances associated with inhibition and removal of inhibitory activity. J Clin Microbiol 36: 3122-6, 1998.

40. Pacheco-Tena C, Alvarado de la Barrera C, Lopes-Vidal Y, et al: Bacterial DNA in sinovial fluide cells of patients with juvenile onset spondyloarthropathies. Br Soc Rheumatol 40: 920-7, 2001.

41. Schnarr S, Putschky N, Jendro MC, et al: Chlamydia and Borrelia DNA in synovial fluide of patients with early undifferentiated oligoarthritis. Arthritis Rheum 44: 2679-85, 2001.

42. Wilkinson NZ, Kingsley GH, Sieper J, Braun J, Ward ME: Lack of correlation between the detection of Chlamydia trachomatis DNA in sinovial fluid from patients with a range of rheumatic disease and the presence of an antichlamydial immune response. Arthritis Rheum 41: 845-4, 1998.

43. Freise J, Gérard HC, Bunke T, et al: Optimised sample DNA preparation for detection of Chlamydia trachomatis in sinovial tissue by polymerase chain reaction and ligase chain reaction. Ann Rheum Dis 60: 140-5, 2001.

44. Pando JA, Yarboro C, Ellaban A, et al: Prevalence of Chlamydia trachomatis by PCR in the synovium of patients with early rheumatoid arthritis (abstract). Arthritis Rheum 38: Suppl 9: S287, 1995.

45. Erlacher L, Wintersberger W, Menschik M, et al: Reactive arthritis: urogentital swab culture is the only useful diagnostic method for the detection of the arthritogenic infection in extra-articulary asymptomatic patients with undifferentiated oligoarthritis. $\mathrm{Br} \mathrm{J}$ Rheumatol 34: 838-42, 1995.

46. Bas S, Cunningham T, Kvien TK, Glennas A, Melby K, Visher TL: Synovial fluid and serum antibodies against Chlamydia in different forms of arthritis: Intra-articular IgA production in Chlamydia sexually acquired reactive arthritis. Br J Rheumatol 35: 548-52, 1996.

47. Bas S, Visher TL: Chlamydia trachomatis antibody detection and diagnostic of reactive arthritis. Br J Rheumatol 37: 1054-9, 1998.

48. Ximenes SC, Fernandez RN, Silva NA: Artrite reativa induzida por Chlamydia trachomatis: análise clínica, laboratorial e terapêutica. Rev Bras Reumatol 36: 359-66, 1996.

49. Machado ACS: Estudo da Infecção por Chlamydia trachomatis em mulheres inférteis por obstrução tubária ou com antecedente de gravidez ectópica: avaliação imunológica e molecular. (Mestrado). Goiânia: Universidade Federal de Goiás, p. 63, 2002.

50. Clad A, Freidank HM, Kunze M, et al: Detection of seroconversion and persistence of Chlamydia trachomatis antibodies in five different serological tests. Europ J Clin Microbiol Infect Dis 19: 932-7, 2000.

51. Angulo J, Castro F, Quispe E, Espinoza LR: A clinical profile of reactive arthritis in a Peruvian series: a pilot study. J Clin Rheumatol 6: 128-35, 2000.

52. Brown MA, Pile KD, Kennedy LG, et al:A genome-wide screen for susceptibility loci in ankylosing spondylitis. Arthritis Rheum 41: 588-95, 1997.

53. Sampaio-Barros PD, Bértolo MB, Marques Neto JF, Samara AM: Espondiloartropatias soronegativas indiferenciadas. Rheuma 6: 5-6, 1998.

54. Cuchacovich R, Japa S, Huang WQ, et al: Detection of bacterial DNA in latin American Patients with reactive arthritis by polymerase chain reaction and sequencing analysis. J Rheumatol 29: 7, 2002.

55. Sieper J, Kingsley GH, Märker-Hermann E: A etiological agents and immune mechanism in enterogenic reactive arthritis. Clin Rheumatol 10: 105-21, 1996.

56. Leirisalo-Repo M, Suoranta H: Ten-year follow-up study of patients with Yersinia arthritis. Arthritis Rheum 31: 533-7, 1988.

57. Loeffelholz MJ, Lewinsk CA, Purohit AP, Herman SA, Buonagurio DA, Dragon EA: Detection of Chlamydia trachomatis in endocervical speciments by polymerase chain reaction. J Clin Microbiol 30: 2847-51.

58. Ossewaarde JM, Rieffe M, Rozemberg-Arska M, Ossnkoppele PM, Nawrocki RP, Van Loon AM: Development and clinical evaluation of a polymerase chain reaction test for detection of Chlamydia trachomatis. J Clin Microbiol 30: 2122-8, 1992. 